\title{
Exploring the Structure of Chinese \\ Consumers' Attitudes Toward Genetically Modified Foods: An Abstract
}

\author{
Wenkai Zhou
}

\begin{abstract}
Traditional unidimensional scales with bipolar measures are often used to assess the overall favorability of consumer attitudes toward genetically modified (GM) foods, despite the limitations such measures carry when used to examine consumer attitudinal ambivalence and indifference (Poortinga and Pidgeon 2006). Given that GM foods are still relatively new and controversial in China and that the country is becoming one of the biggest food importers globally, it is imperative that food marketers and researchers develop a comprehensive understanding of Chinese consumers' attitudes toward GM foods.

The goal of this research is to explore the structure of Chinese consumers' attitudes through a multivariate-oriented approach aimed at separating perceived benefits, perceived risks, attitudinal ambivalence, and attitudinal indifference using the four-way typology approach developed by Poortinga and Pidgeon (2006). A questionnaire concerning GM foods was distributed to the students of a large-scale university in Northwest China. Respondents represented students from all across the nation and were asked to indicate the extent to which they agree or disagree with the risk and benefit statements provided in the questionnaire.

Results show that Chinese consumers' attitudinal valence, ambivalence, and indifference can be separated using factor analysis due to the various degrees of perceived benefits coexisting with various degrees of perceived risks in a consumer's attitude formation process. Additionally, both positive and negative attitudes are largely related to food safety concerns in China. Nevertheless, consumers with positive attitudes are optimistic and believe that GM food technologies could help increase agricultural efficiency; whereas consumers with negative attitudes are pessimistic and worry that GM crops may do harm to the ecosystem and human body in the long run.
\end{abstract}

\footnotetext{
W. Zhou $(\bowtie)$

University of Wisconsin-Green Bay, Green Bay, WI, USA

e-mail: zhouw@uwgb.edu
} 